\title{
Cross-linguistic Transfer (from L1 to L2, L2 to L1, and L2 to L3) of Reading Strategies in a Multicompetent Mind
}

\author{
Seyed Hassan Talebi \\ Department of English Language and Literature, the University of Mazandaran, Babolsar, Iran
}

\begin{abstract}
Taking a process and product view of reading, this paper attempts to explore the relationship between languages in one mind from Cook's multi-competence perspective. According to multi-competence view, L1 and L2 (or L2s) which are in one mind form a linguistic super-system (Cook, 2004) and not systems which are completely separate. In studies of language transfer, the general idea is that languages have effects on each other. To the purpose of this paper, three studies conducted by the author on the effects of L1 on L2, $\mathrm{L} 2$ on L1, and $\mathrm{L} 2$ on $\mathrm{L3}$ will be provided. The common finding in all these studies is improvements in the process of reading in any given language will result in improvements in the process of reading in other languages. However, the same transferability power that can be conceived for the process of reading cannot be conceived for the product of reading as factors such as directionality of transfer and language proficiency interfere with this. It is recommended that since the process aspect of reading in different languages in one mind is transferable, native or foreign language teachers take this aspect of the relationship between languages as seriously as possible so that its effects can be witnessed both in the language of instruction and other languages that exist in the mind of the reader, be it L1, L2 or any further language. An advantage of this is that an increase in the process or reading will also result in an increase in the product of reading both in the language of instruction and any other language in mind if other conditions are met.
\end{abstract}

Index Terms - cross-linguistic transfer, L1, L2, L3, multi-competence, reading strategies

\section{INTRODUCTION}

One of the significant aims of language classes is to improve effective reading in all students. Among the four main skills, reading plays a pivotal role in learning a foreign language. Therefore, the matter of strategic reading has been considered as a bridge to success by many reading researchers and teachers in recent years. Since in the current world of communication it is a commonplace to learn at least a foreign language, it is a necessity for language instructors and/or language learners to know about the nature of the relationship of languages in one mind and to know in what ways languages in one mind influence each other. What follows touches upon language transfer studies, strategic reading, multi-competence view, and a report of three experimental studies on the relationship of languages in language learners' mind. Finally, conclusions and recommendations are presented.

\section{LANGUAGE TRANSFER}

In the 50s and 60s, under the influence of behaviorism and structuralism, language transfer studies became common practice in second/foreign language studies. Odlin (1989) states linguistic transfer is "the influence resulting from similarities and differences between the target language and any other language that has been previously (and perhaps imperfectly) acquired" (p. 27). L1 influence on L2 is known as 'substratum transfer' (Odlin, 1989, p. 169). Different aspects of language including the phonetic, phonological, semantic, syntactic, and morphological aspects can be under this influence. On the other hand, 'borrowing transfer' (ibid, 1989, p. 169) or 'reverse transfer' (Cook, 2003) happens when the direction of linguistic transfer is the reverse.

Transfer was assumed to be either positive or negative. It was believed that negative transfer, which is also known as language interference, was the main source of problems for learners. This idea formed the basis of the so-called Contrastive Analysis Hypothesis (Odlin, 1989) whose main tenet was that structural differences between languages equal difficulty and it is this difficulty that leads to interference errors in L2. However, research showed that even similarities can be problematic and dissimilarities seem to facilitate SLA (Catford, 1964). Transfer was not considered as the main source of problem in SLA any more when based on the Chomskian Universal Grammar theory (see Chomsky, 1969) L1 and L2 acquisition were considered equivalent developmental processes. According to this theory, second language acquisition came to be regarded as a creative construction process rather than the transfer of old habits from L1 to L2 (Dulay and Burt, 1975). Therefore, developmental errors were believed to occur as a result of learners' strategies to make learning easier (Taylor, 1975). This view was also criticized because it considered a very small role for transfer in the process of L2 acquisition (Sharwood Smith, 1996). This led to the argument that both transfer and creative construction are influential factors in learning a second and/or foreign language (Danesi, 1995). Among the 
five processes critical to the learning of a target language, language transfer is regarded as one important process. The remaining four processes are overgeneralization, transfer-of-training, L2 learning strategies, and L2 communication strategies (Selinker, 1972). If we regard linguistic transfer as an influential variable in L2 learning, then we should shift our focus from the behaviorist principle of transfer to the transfer of processing strategies (see Sridhar, 1980). This is especially helpful if we teach for transfer between skills within a language, or between languages within a skill.

\section{STRATEGIC READING}

Reading in L1, L2 or any further language is active skill in which readers construct meaning based on the print (Koda, 2007). In literature, there is distinction between the product and process of reading (Bossers, 1991, Sarig 1987, Taillefer and Pugh 1998). By process it is meant various strategies that readers use. Reading strategies questionnaire, interviews or think-aloud techniques are mostly used for measuring the process of reading. Product of reading or the reading score is measured by reading comprehension tests. The trend in EFL reading instruction shifted from teaching texts to teaching readers (Hamp-Lyons, 1985). Therefore, one of the goals of reading research is to probe into learners' reading strategies. "Reading strategies are of interest not only for what they reveal about the ways readers manage their interactions with written text, but also for how the use of strategies is related to effective reading comprehension" (Carrell, 1998, p. 2). Reading strategies are regarded by Urquhart and Weir (1998, p. 95) as "ways of getting around difficulties encountered while reading." Effective readers monitor the process of reading, are conscious of their own linguistic and cognitive resources, and look for contextual clues. We call these readers as strategic readers and their behavior in reading as 'strategic reading. (Koda, 2005, p. 204)

\section{Multicompetence VieW}

It is a commonplace in language transfer studies to say that the first language would have a positive or negative effect on the second language. A good example is the speech of L2 learners in which there is a trace of L1 accent. However, Cohen (1995) found that bilingual or multilingual people shift between languages in their mind. Pavlenko and Travis (2002, p. 191) referred to 'bidirectional transfer' which is the interaction between the two languages in different perspectives. The concept of the effects of L2 on L1 comes from the notion of 'multi-competence' (Cook, 2003). Before the introduction of the idea of multi-competence, L1 and 'interlanguage' (Selinker, 1972) were believed to be two separate systems in one mind and there was no umbrella term connoting the knowledge of both. Therefore, 'multicompetence' was put forward to refer to the knowledge of languages in the same mind. (Cook, 1991)

Multi-competence regards the languages in mind as a whole rather than as separate L1 and interlanguage components. Cook (2004) states "since the first language and the other language or languages are in the same mind, they must form a language super-system at some level rather than completely separate systems." Cook (2003) explains about three possible models for the relationship of languages in mind: 1) The Separation Model. As the name speaks for itself, it regards the languages to be "in watertight compartments" in mind (p. 6). Since, the second language user does not connect the languages in their mind, discussions about the effects of L2 on L1 in this model is of no justification. 2) The Integration Model which takes quite the opposite view. It considers one system for different languages in mind. It considers a balance between components of this single system and there is no discussion about the influence of languages on each other. We cannot count languages in mind as first, second, or third languages because they form a unitary system. However, this model is on no firm grounds since L2 users can separate languages in mind (Francis, 1999; Cook 2002). 3) The interconnection model. This model falls in between these two extreme models. In itself, it is subcategorized into two models. First is the 'linked-languages model', viewed a variant of the separation model. According to this model, the separate components of languages are in interaction with one another. Therefore, studies of language transfer are discussed in this model. Second is the 'partial integration model', driven from the concept of the total integration model. It holds that the two linguistic systems have partially overlapping areas in one mind. "It does not distinguish between languages in the same area of overlap, but sees how the single conjoined system differs from monolingual versions of either language. There may be shared overlapping vocabulary, syntax, or other aspects of language knowledge" (Cook 2003, p. 8).

However, with regard to the ideas and models of the relationship of languages in mind mentioned above, the interesting question is which model can be conceived for the relationship of reading in L1 (Persian language), L2 (English language) and L3 (Arabic language) in the mind of learners when they come to read in any given language. To answer this question, three studies were conducted by the author in each of which two languages are studied simultaneously. What follows is an overview of them.

\section{A. Study one: Strategic reading in L1 (Persian) and L2 (English): one system or two systems?}

Many instructors hold that since students fail to read effectively in L1, they fail to read effectively in L2 (Alderson, 1984). This study aimed to determine if L1 (Persian) strategic reading differs from L2 (English) strategic reading. Therefore, the following questions were raised: 1) Does the instruction of reading strategies in Persian influence the reading strategies awareness and use in Persian, as well as in English?, and 2) Does the instruction of reading strategies in L1 have any effects on increasing reading comprehension in L1 (Persian) and L2 (English)? The subjects, who were Iranian EFL learners at intermediate and advanced proficiency levels as determined by Nelson test of proficiency, were 
put into two groups of control and experimental. 30 students participated in each group. Then, two test batteries of reading, one in Persian and another in English were administered as pre-tests to them. Immediately after these reading tests, a third pre-test, a checklist of reading strategies was distributed to determining what strategies were employed in Persian and English reading tasks. This checklist was adopted from Taillefer and Pugh (1998). It was translated into Persian for learners to feel more comfortable with it. After all the pretests were distributed, the experimental group received instruction of reading strategies in L1 with L1 texts. To this end, the components suggested by Winograde and Hare (1988, cited in Carrell, 1998.p.5) were used. They include What the strategy is; Why, how, when, and where a strategy should be used; and, how to evaluate use of strategy. The nature of the texts used in treatment was similar to that of texts used in Persian reading tests in terms of genre of the text, length of the text, and general content of the text. The treatment lasted for eight sessions of 35/40-minutes and, both experimental group and control group were distributed the posttests after the treatment. Analysis of data showed improvements in reading strategies awareness and use in L1 and L2 at both proficiency levels. However, improvements in L1 reading performance were not observed in L2 reading performance after reading strategies instruction in L1. It showed the transferability of strategies awareness and use from L1 to L2, but the effective use of strategies in L2 so that it results in improved L2 reading performance requires more practice in L2 reading strategies instruction with L2 texts.

\section{B. Study two: The relationship between reading in L2 (English) as the first foreign language and L3 (Arabic) as the second foreign language: which model: total separation, total integration, or interconnection?}

Learning of a third (or a second foreign) language for a person who has already learnt a foreign language is not a new experience. The intriguing question is if L3 learning draws upon L2 learning experience. This study investigated if reading strategies awareness as well as reading performance in the first and second (English and Arabic, respectively) foreign languages would improve significantly through instruction of reading strategies in L2. 120 Iranian students at pre-university level composed the participants in this study. Simultaneously, they had English and Arabic courses. They were all male and their age ranged from 18 to 19 years. First, the Proficiency test (Nelson, Series 300B) was administered to 210 students to identify students of intermediate and advanced language proficiency levels. They composed the participants of the control and experimental groups. For determining the current abilities of students in L2 and L3 reading tasks, the reading tests in L2 and L3 were administered as pretests to students. These tests were immediately followed by the reading strategies checklist, measuring the strategies awareness and use of students for in L2 and L3. The questionnaire was adopted from the Sheorey and Mokhtari (2001) as an immediate retrospective measure of reading behavior. Following the pretest, the treatment of was given in English, along with normal classroom materials, but the control group just underwent their regular classroom instructions. The measure suggested by Winograde and Hare (for more explanation refer to study one, above) was used to teach students how to read strategically. In addition, the teacher think-aloud technique was used as a common technique of teaching reading strategies to model strategic reading. That is, each single strategy was explained to the students. The students were shown how to use it while reading and they were instructed how to orchestrate use of all the strategies in different reading tasks given to them. The treatment was in ten sessions, each lasting one hour. After the treatment, posttests were given to students. This study showed that reading strategies instruction in the first foreign language improves reading strategies awareness and use, as well as reading ability both in the first and second foreign languages, evidence of the influence of the first foreign language on the second foreign language.

\section{Study three: Reading in L2 (English) and L1 (Persian): An Investigation into Reveres Transfer of Reading Strategies} from $L 2$ to $L 1$

The same way that one conceives impacts of L1 on L2, L2 effects on L1 are also conceivable. As Cook (2003, p.1) states "the first language of people who know other languages differs from their monolingual peers in diverse ways" from vocabulary to pragmatics. This paper investigate if reading strategies awareness and use as well as the reading score, both in the foreign language (English) and the native tongue (L1) would improve through reading strategies instruction in L2 (English). To this end, two groups of Iranian EFL learners, from two English proficiency levels (intermediate and advanced as determined by proficiency test Nelson) were selected and put into control and experimental groups. Each group was composed of 30 students. To assess the actual reading performance of the participants in L2 and L1 reading, two series of tests of reading, one in English and another in Persian, were administered to the students as pretests. The strategic approach in L2 and L1 was measured using a five-point Likert scale questionnaire of cognitive and metacognitive reading strategies, ranging from Never to Always true of me. The instrument was translated into Persian so that students would understand it clearly. Following the pretest, the experimental group underwent the treatment in L2, but the control group just received their regular classroom materials. Scaffolding is a technique for teaching reading. In this study for, two main steps of scaffolded reading from Graves and Graves (1994) namely, the planning and the implementation step, were used. For the planning phase, the teacher considers learners variables (such as their needs, interests, strong and weak points, and background knowledge), text variables (such as its topic, theme, genre, readability and comprehensibility), and the reading purpose(s). For the implementation step, before reading, while reading, and after reading activities were conducted. People (teacher and peers) scaffolding (in McEwan, 2004) was also used and implemented using the model of Collaborative Strategic Reading (CSR) by Klingner and Vaughn (1998). CSR consists of four comprehension strategies, including, (a) preview 
(before reading); (b) click and clunk (while reading); (c) get the gist (after reading); and, (d) wrap-up (after reading), to be used in small cooperative groups. The participants received post-tests after the treatment to the experimental group. The study shoed reading strategies instruction in L2 results in improvements in reading strategies awareness and use as well as reading ability not only in L2 (in English) but also in L1 (in Persian).

\section{CONCLUSIONS AND IMPLICATIONS}

From the perspective of language transfer studies, it is all agreed upon to say while reading in a given language, readers have access to other languages exiting in their mind. Therefore, an improvement in any language can somehow result in improvements in other languages. A clear manifestation of such improvements can be clearly found in the process aspect of reading. As shown above, reading strategies awareness and use transfers cross-linguistically from L1 to L2, L2 to L3, and L2 to L1. It seems there is no restraint on this kind of transfer (that is, transfer of strategies or the process of language learning). The idea of transfer falls in the linked languages model of the relationship between languages introduced by Cook. When strategic students come to experience reading in a new language, they are not blank in mind about their task. They are aware of the how of reading in their new reading experience.

Strategies oriented instruction is a learning-based approach whose goal is to create autonomy in learning and increases proficiency. As Tseng, et. al $(2006,78)$ mention the majority of work in learning strategies instruction have tried "to explore ways of empowering language learners to become more self-directed and effective in their learning." In fact, instruction of learning strategies helps students to get more conscious of strategies, to learn how to orchestrate them efficiently, and to learn when, and how to transfer strategies to new contexts. (Brown, 2001) However, this is not always the case for the product of reading. Although strategic reading is a necessary condition for the improvement of the product of reading and reading comprehension, the mere awareness and use of the strategies does not make a reader an effective reader. Then, two factors are important here. One is how effectively these strategies are used. It is the effective use, and not the mere use of the strategies that makes a reader an accomplished strategic reader. Another factor is language dominance. If L1 (dominant language) reading strategies transfer to L2 (less dominant), there is the possibility for these strategies to be short circuited due to low proficiency level in L2. This will make language competence interfere with reading performance. (Clarke, 1980) However, if L2 reading strategies which were effectively used in L2 transfer to L1, improvements in L1, both in process and in product can be observed. This is because the direction of this transfer is from a less dominant to a more dominant language. In this case there is no talk of short circuiting or L1 proficiency problem. However, regardless of the direction of transfer and proficiency level of students, improvements in the process and product of reading in L2 resulted in the same improvements in L3.

The results of these three studies are similar to the findings as reported in the following investigations. Hardin (2001) found that bilingual learners transferred learning strategies from one language to another irrespective of their level of proficiency. Hua (1997, in Koda, 2005) made a comparison of use of reading strategies among Chinese ESL students in Chinese and English and found that readers used same comprehension strategies in the two languages. This suggests that reading strategies are transferable cross-linguistically, irrespective of linguistic distance. Jimenez et al. (1995) took a unitary view toward reading. They found that bilingual readers regard many commonalities between reading in L1 (Spanish) and L2 (English). Therefore, it can be concluded that languages have some areas of difference, as in sounds, letters, grammatical surface structure, culture, etc., and some areas of overlap. Reading strategies fall in the area of overlap between languages as claimed in the linked-languages model, making a link between languages in one mind. People with two or more languages in their minds have a single, not multiple knowledge base of strategies for all languages. Pedagogically, it can be implied that it does not matter from where, (L1, L2, or any further language) we begin teaching our language learners how to read. The effects will be seen in other languages while doing the reading tasks. Therefore, based on the multi-competence view, an L1 teacher, as an example, eases the job of teachers of other languages by teaching the language-related areas which fall in the area of overlap as claimed in the linked languages model. This will also change the attitudes of language learners towards learning a further language or making up for problems in a previously learnt language.

\section{REFERENCES}

[1] Alderson, J.C. (1984). Reading in a foreign language: a reading problem or a language problem? In J.C. Alderson and A. H. Urquhart (eds.), Reading in a Foreign Language. London: Longman.

[2] Bossers, B. (1991). On thresholds, ceilings and short-circuts: The relation between L1 reading, L2 reading and L2 knowledge. AILA Review 8, 45-60. doi: 10.1080/10862969509547899

[3] Brown, H. D. (2001). Teaching by principles: an interactive approach to language pedagogy (2nd Ed.). White Plains, NY: Addison Wesley Longman.

[4] Carrell, P. L. (1998). Can reading strategies be successfully taught? http://jalt-publications.org/old_tlt/files/98/mar/carrell.html (accessed 10/1/2013)

[5] Catford, J. C. (1964). The teaching of English as a foreign language. In R. Quirk \& A. H. Smith (Eds.), The Teaching of English. Oxford: Oxford University Press. pp. 137-159

[6] Chomsky, N. (1969). Syntactic Structures. The Hague: Mouton.

[7] Clarke, Mark. A. (1980). The short circuit hypothesis of ESL reading - or when language competence interferes with reading performance, The Modern Language Journal 64.2, 203-209. DOI: 10.1111/j.1540-4781.1980.tb05186.x 
[8] Cohen. A. D. (1995). In which language do / should multilinguals think? Language, Culture, and Curriculum 8, 99-113. Doi: $10.1080 / 0790831950952519$

[9] Cook, V. J. (1991). The poverty of the stimulus argument and multicompetence Second Language Research, 7.2, $103-117$. doi:10.1177/026765839100700203

[10] Cook, Vivian (2002)

http://homepage.ntlworld.com/vivian.c/Writings/Papers/BasingTeaching.htm, (accessed 10/1/2013)

[11] Cook, Vivian (2003). Changing the first language in the L2 user's mind. Draft of Intro to L2 effects on the L1. http://homepage.ntlworld.com/vivian.c/Writings/Papers/FXintro.htm (accessed 10/1/2013)

[12] Cook, Vivian (2004). Bilingual cognition and language teaching. Draft of paper for talk in Taiwan. http://homepage.ntlworld.com/vivian.c/Writings/Papers/BilCog\&Teaching.htm (accessed 10/1/201)

[13] Danesi, M. (1995). Contrastive analysis and second language teaching today: the legacy of Robert J. Di Pietro. In J. FernándezBarrientos Martín, \& C. Wallhead, C. (eds.), Temas de Lingüística Aplicada. 209-231.

[14] Dulay, H. C., \& Burt, M. (1975). Creative construction in second language learning and teaching. In M. Burt \& H. C. Dulay (eds.), New directions in second language learning, teaching, and bilingual education (pp. 21-32). Washington, DC: Teachers of English to Speakers of Other Languages.

[15] Francis, W. (1999). Cognitive integration of language and memory in bilinguals: semantic representation. Psychological Bulletin, 125.2, 193-222. doi.apa.org/psycinfo/1999-10106-004

[16] Graves, M. F. \& Graves, B. B. (1994). Scaffolding reading experiences: Designs for students' success. Norwood, MA: Christopher Gordon.

[17] Hamp-Lyons, L. (1985). Two approaches to teaching reading: A classroom based study. Reading in a Foreign Language, 3 , 363-373.

[18] Hardin, V. (2001). Transfer and variation in cognitive reading strategies of Latina fourth-grade students in a late-exit program. Bilingual Research Journal 25.4, 1-21.

[19] Hua, T. (1997). The relationship between reading comprehension processes in L1 and L2. Reading Psychology 18, $249-301$.

[20] Jimenez, R., Garcia, G., \& Pearson, P. (1995). Three children, two languages, and strategic reading: Case studies in bilingual/monolingual reading. American Educational Research Journal 32, 67-97. doi: 10.3102/00028312032001067

[21] Klingner, J. K. \& Vaughn, S. (1998). Using collaborative strategic reading. Teaching exceptional children, 30.6, 32-37.

[22] Koda, K. (2005). Insights into second language reading: A cross-linguistic approach. Cambridge. Cambridge University Press.

[23] Koda, K. (2007). Reading and language learning: Crosslinguistic constraints on second language reading development. Language Learning 57.1, 1-44. DOI: 10.1111/0023-8333.101997010-i1

[24] McEvan, E. K (2004). Seven strategies of highly effective readers. Using cognitive research to boost K-8 achievement. Thousand Oaks, California, Corwin press.

[25] Odlin, T. (1989). Language transfer. Cambridge, Cambridge University Press.

[26] Pavlenko, Aneta \& Travis, Scott (2002). Bidirectional transfer. Applied Linguistics, 23.2, 190- 214.

[27] Sarig, G. (1987). High-level reading in the first and in the foreign language: Some comparative processes data. In J. Devine, P. Carrell \& D. E. Eskey (eds.), Research in Reading in English as Second Language, 105-120.

[28] Selinker, L. (1972). Interlanguage. International Review of Applied Linguistics, X.3, 209-231.

[29] Sharwood Smith, M. (1994). Second language learning: theoretical foundations. Harlow: Longman.

[30] Sheorey R. \& Mokhtari, K. (2001). Differences in the Metacognitive Awareness of Reading Strategies among Native and Nonnative Readers. System, 29.4, 431-449. DOI: http://dx.doi.org/10.1016/S0346-251X(01)00039-2

[31] Sridhar, S. N. (1980). Contrastive analysis, error analysis, and interlanguage. In J. Fisiak (ed.), Contrastive linguistics and the language teacher. Oxford: Pergamon Press.

[32] Taillefer, G. \& Pugh, T. (1998). Strategies for professional reading in L1 and L2. Journal of Research in Reading, 21.2, 97-108. DOI: $10.1111 / 1467-9817.00047$

[33] Taylor, B. P. (1975). Adult language learning strategies and their pedagogical implications. TESOL Quarterly, 9, $391-399$.

[34] Tseng, Zoltan Dornyel \& Norbert Schmith (2006). A New Approach to Assessing Strategic Learning: The Case of SelfRegulation in Vocabulary Acquisition. Applied Linguistics, 27.1, 78-102. doi: 10.1093/applin/ami046

[35] Urquart, A. \& Weir, J. C. (1998). Reading in a Second Language: process and product. London Longman.

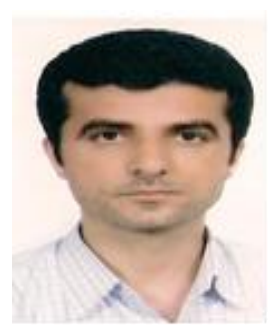

Seyed Hassan Talebi is an Assistant Professor in TEFL, in the Department of English Language and Literature at the University of Mazandaran, Iran. He received his Ph.D. from the Department of Studies in English Language of Mysore University, Mysore, India in 2008. He is currently offering courses at graduate and postgraduate levels at the University of Mazandaran. His research interests include strategic reading, cross-linguistic transfer of reading strategies, ESP reading, and learner autonomy. 